\title{
Morcellation in gynecology: short review and suggestions from Turkish Society of Minimally Invasive Gynecologic Oncology
}

\author{
(D) Salih Taşkın ${ }^{1}$, (D) Bulut Varlı², (D İbrahim Yalçın³, (D) Fırat Ortaç², (D Çağatay Taşkıran4, (D) Mete Güngör 5 \\ 1Department of Gynecologic Oncology, Ankara University Faculty of Medicine, Ankara, Turkey \\ 2Department of Obstetrics and Gynecology, Ankara University Faculty of Medicine, Ankara, Turkey \\ 3Department of Gynecologic Oncology, Ondokuz Mayıs University Faculty of Medicine, Samsun, Turkey \\ ${ }^{4}$ Department of Gynecologic Oncology, Koç University Faculty of Medicine, İstanbul, Turkey \\ 5Department of Gynecologic Oncology, Acıbadem University Faculty of Medicine, İstanbul, Turkey
}

\section{Abstract}

\begin{abstract}
Morcellation allows the removal of a large uterus and fibroids through small incisions with minimally invasive surgery. It helps to prevent the complications associated with large incisions in both hysterectomy and myomectomy operations. Currently, there is much debate regarding the use of power morcellation in laparoscopic hysterectomy and myomectomy, mainly due to the risk of peritoneal dissemination of undiagnosed uterine sarcomas. Unfortunately, there is no valid pre-operative diagnostic method that can differentiate sarcomas from myomas, and the currently available scientific literature regarding morcellation is insufficient. As the Turkish Society of Minimally Invasive Gynecological Oncology, we present our consensus opinion and suggestions for the preoperative evaluation and morcellation of fibroids, in line with the recent literature. (J Turk Ger Gynecol Assoc 2021; 22: 53-7)
\end{abstract}

Keywords: Myomectomy, hysterectomy, morcellation, laparoscopic surgery, vaginal surgery

Received: 24 June, 2020 Accepted: 09 December, 2020

\section{Introduction}

Morcellation is performed for reducing the size of a uterus or myoma, to ease extraction of tissues from the abdominal cavity. The history of procedure goes back to the $19^{\text {th }}$ century. The first applications were mechanically made after vaginal surgery to reduce the size of the tissue (1). In this way, vaginal surgery can be also performed in when a large uterus is present, which previously generally required open surgery. In subsequent years, minimally invasive surgery started to replace most open and vaginal procedures and, as a result, the need for a new way to extract huge uteruses and myomas from smaller incisions arose.

In 1976, a laparoscopic manual morcellator, which can work through $15 \mathrm{~mm}$ and $10 \mathrm{~mm}$ incisions, was produced (2). The technical properties of subsequent equipment have improved and devices have been replaced by electromechanical morcellators which has also reduced the time required for tissue extraction (3). By 1993, the use of a morcellator with more advanced features was approved by the Food and Drug Administration (FDA) (3).

A morcellator is used when performing hysterectomy or myomectomy for large uteruses during minimally invasive surgery to avoid open surgery-related morbidities. On the other hand, if morcellation is performed in the presence of uterine malignancy, especially uterine sarcoma, which usually cannot be diagnosed preoperatively, this may cause the disease to upstage and have a negative effect on the prognosis $(4,5)$.

In 2013, a patient was diagnosed with leiomyosarcoma after total hysterectomy, which was performed with a minimally 
invasive approach for a presumed benign uterine fibroid and in the later staging surgery, intraperitoneal spread was observed. After this case was published, a debate started about morcellator usage and in 2014 the FDA discouraged the use of laparoscopic power morcellation during hysterectomy or myomectomy for uterine fibroids (6). In November 2014, the FDA updated its recommendations and specified contraindications for morcellation (7):

1. Morcellators are contraindicated for removal of uterine tissue containing suspected fibroids in patients who are peri- or postmenopausal or are candidates for en-bloc tissue removal through the vagina or mini-laparotomy incision.

2. Morcellators are contraindicated in patients with uterine fibroids suspicious for malignancy.

However, the scientific basis of this advice was not clear and definition of perimenopause was not explained. Despite the FDA's clear advice against morcellation, some national societies have not made a strict recommendation to prohibit morcellation (8-12).

The Turkish Minimally Invasive Gynecologic Oncology Society formed a working group on this subject and prepared suggestions in the light of current literature, which will guide both surgeons and patients.

\section{Uterine sarcoma types and occult sarcoma risk in presumed myoma}

Endometrial adenocarcinoma constitutes nearly 95\% of all uterine malignant tumors (13). Mostly, diagnosis is obtained through pre-operative endometrial sampling and it is rarely diagnosed incidentally after hysterectomy. However, preoperative diagnosis of uterine sarcomas, which make up 5\% of uterine tumors, is not possible most of the time (13). These patients are at highest risk from inappropriate morcellation.

Leiomyosarcoma, endometrial stromal sarcoma and rhabdomyosarcoma are most common types of uterine sarcomas. Unfortunately, the exact rate of post-operative sarcoma diagnosis is not known in patients who are presumed to have benign fibroids pre-operatively. Since this is a rare situation, most of the relevant studies are retrospective and contain much bias. In a report of the FDA, the incidence of all sarcomas and leiomyosarcomas were reported as 1/350 and $1 / 458$, respectively $(6,7)$.

However, it is also seen that this rate varies according to the method of studies. In a meta-analysis of 133 studies (14), occult leiomyosarcoma risk was calculated as 1/1960 when both retrospective and prospective studies were included, but this rate dropped to $1 / 8300$ when only prospective studies were considered. In studies investigating the incidence of sarcoma in patients who underwent morcellation during myomectomy or hysterectomy for presumed benign disorders, the highest rate was reported as $0.6 \%$ (15). Recently, two studies from Turkey reported the incidence of occult uterine sarcomas $(16,17)$. Topdagi Yilmaz et al. (16) reported the incidence of unexpected uterine sarcoma in patients who underwent hysterectomy for benign indications as $0.6 \%$ (7/1050). In addition, Yorgancı et al. (17) investigated the rate of occult uterine sarcoma in 18,604 women who underwent hysterectomy or myomectomy with a pre-operative diagnosis of uterine leiomyoma and occult uterine sarcoma incidence was 0.3\% (56/18604).

\section{Possible adverse effects of morcellation: sarcoma and benign conditions}

Morcellation can be performed manually, either using scissors or scalpel, or power morcellation can be performed using electromechanical devices. It can be performed during minimally invasive surgery or vaginal surgery. The procedure can be performed un-contained, contained (in bag) or using a mini-laparotomic incision.

After hysterotomy, regardless of morcellation, malignant cells, if present, may spread to the peritoneal cavity. During morcellation, the specimen is divided into smaller pieces in the peritoneal cavity and, irrespective of the malignancy potential, some problems may arise including spread of tissues into the peritoneal cavity, incomplete removal of tissue fragments, and microscopic residues becoming peritoneal implants. Thus, an increased incidence of benign peritoneal diseases, including parasitic leiomyoma, endometriosis and extensive intraperitoneal leiomyomatosis, have also been reported after morcellation (18). It should be kept in mind that morcellation significantly increases the risk of these benign sequelae compared to the risk of spreading malignancies.

Long-term survival is not favorable in patients with leiomyosarcoma (19). Besides, there are publications supporting the idea that morcellation can worsen the stage and negatively affect survival in the presence of malignancy $(5,20,21)$. In a study evaluating the effect of morcellation on survival, in the "no morcellation" group, 1-year mortality rate was $5.3 \%$ and in the morcellation group this rate was $18.2 \%$ (20). Patients who were diagnosed with stage 1 sarcoma or smooth muscle tumors of uncertain malignant potential during initial surgery were operated after a median of 33 days (22) and widespread peritoneal disease was found in $28 \%$ and $25 \%$ of the patients, respectively (22). Although the studies are retrospective, it was found that hysterotomy affects survival negatively compared to intact hysterectomy. In morcellated sarcoma cases, the risk of abdominopelvic spread increased significantly (44\% vs $12.9 \%$ ) and survival decreased significantly compared to those in whom morcellation was not performed (5). In another case series, the 1-year mortality rate was found to be significantly higher in the morcellation group (20). Result 
of a meta-analysis also supported increased risk of recurrence and death (21).

After morcellation, integrity of the specimen is damaged and this can cause both difficulty in pathological examination and it may also adversely affect the diagnosis and staging procedures (23).

\section{In-bag morcellation}

In order to prevent or reduce the adverse effects of intraperitoneal uncontained morcellation, morcellation in a closed peritoneal space has been suggested as a possible solution. The most popular method is in-bag morcellation but its potential for avoiding harmful effects and superiority over other morcellation strategies is unconfirmed and needs to be studied further. In addition, there is no consensus opinion from interested societies that in-bag morcellation will prevent morcellation related complications.

In studies evaluating a limited number of patients, tissue or dye leakage or spreading out of the bag were observed in 9-33\% of the cases when morcellation was performed in the bag $(24,25)$. Some of the leaks, perhaps, represent microscopic spread. However, there is no data yet on whether this will affect survival in case of malignancy.

\section{Preoperative sarcoma diagnosis}

Risk factors include age, history of pelvic irradiation, tamoxifen usage, genetic syndromes (i.e. hereditary leiomyomatosis and renal cell cancer mutation, Lynch syndrome) and history of retinoblastoma in childhood and have been shown to increase the risk of sarcoma (9). If the lesion shows rapid growth in a 3 -month period (exact clinical and radiological criteria have not been determined), and especially if there is a lesion greater than $8 \mathrm{~cm}$ in the menopausal period, or lesions with central necrosis, heterogeneous appearance, non-calcified cystic degeneration and irregular high blood supply may arouse suspicion of sarcoma (9). However, none of these criteria is effective enough to establish a definitive preoperative diagnosis (26).

\section{Preoperative endometrial biopsy}

Although it is an effective diagnostic method in the diagnosis of endometrial pathologies, the effectiveness of endometrial biopsy in the diagnosis of uterine sarcomas is low. It was shown that endometrial biopsy identified only $36 \%$ of leiomyosarcomas in submucous lesions (27). In the diagnosis of endometrial stromal sarcoma, the sensitivity was 33\% (28). Localization of lesions can vary significantly, and therefore endometrial biopsy is not considered as a useful preoperative diagnostic test in these lesions. Besides, in asymptomatic women, no benefit has been shown. However, endometrial biopsy can help clinicians in patients with preoperative abnormal uterine bleeding.

\section{Imaging methods}

Ultrasonography is the first and most frequently used radiological method but differential diagnosis between leiomyoma and sarcoma cannot be made always $(29,30)$. In color doppler, atypical vessel pattern, low resistance index and high systolic velocity is observed in sarcomas (31). However, depending on variables, such as location of the lesion, menopausal status of the patient, and size of the lesion, ultrasonographic features of sarcoma and leiomyomas may overlap and are not distinctive in the majority of cases.

Magnetic resonance imaging (MRI) may show more diagnostic accuracy in differentiation of leiomyoma and sarcoma $(13,32)$. Features such as necrosis, rapid growth, intense contrast enhancement, and restriction on diffusion-weighted imaging can ease the diagnosis and help to differentiate sarcomas from leiomyomas. However, specificity and positive predictive value are low (32). If diffusion-weighted images and contrast imaging are used, discrimination can increase (33). However, despite studies that reported diagnostic efficacy as $88 \%$ with these methods (34), some studies have reported imprecision in the successful distinction of fibroid and sarcoma (33). Therefore, the role of MRI should be evaluated in further studies involving more patients. Also, MRI is not recommended for routine use in all lesions and should be used after ultrasonography, in the presence of clinical suspicion (13).

Computed tomography and a positron emission tomography scan are not helpful to discriminate leiomyoma and sarcoma, and they should not be used pre-operatively, solely for this purpose.

\section{Biochemical markers}

It is thought that elevated levels of lactate dehydrogenase (LDH) may serve as an indicator of necrosis in the tumoral tissue and invasion into the intravascular area in the presence of sarcoma. Studies have shown that increased levels of LDH are significantly more frequent in the sarcoma group than in the leiomyoma group (35). In one study, the diagnostic success rate of a combination of $\mathrm{LDH}$ and MRI was reported to be $100 \%$ (32). Success in evaluations with LDH subtypes was also reported, investigating $\mathrm{LDH}$ isozyme type 1 and 3 (32,35). In a study using receiver operating characteristic curve analysis for the prediction of sarcoma in the pre-operative period, the optimum cut-off value for LDH was 279.0 U/L (36). However, further studies are needed to confirm the utility of LDH in differential diagnosis. 


\section{Intraoperative management}

Some characteristics of uterine lesions raise suspicion for sarcoma intraoperatively. These are: no clear mass borders like leiomyoma; no bulging during uterine incision; soft, homogenous, yellowish appearance; and increased tissue fragility. However, these features may also present in patients with degenerative myoma or after use of pre-operative hormonal treatment. In advanced stages, sarcomas may lead to overgrowth and local invasion to adjacent organs (e.g bladder, rectum). Intraoperative frozen-section analysis does not have much efficacy and diagnostic accuracy was reported as only $11-38 \%$ (37).

\section{Postoperative management}

A uniform clinical management plan for patients with morcellated uterine sarcoma does not exist. Several authors have advised completion of surgery with hysterectomy in case of myomectomy and the abdominal cavity can be evaluated for the presence of metastatic implants (38). Also, patients with late surgical ( $>30$ days) re-exploration had a higher mortality rate (39).

\section{Opinions and suggestions}

Since uterine sarcomas are rare and most of the available data are based on retrospective studies, it is difficult to provide certain and conclusive suggestions. The following opinions and suggestions are presented in line with the available data. The following statements can be potentially modified or altered as per new evidence.

1. There is no method that can definitively differentiate sarcomas pre-operatively in patients who are going to be operated with a preliminary diagnosis of uterine myoma.

2. Uterine sarcomas usually occur in women of advanced age, but there is no exact age limit. Especially in patients aged $>35$ years who are being considered for morcellation, it is recommended that the risk factors should be investigated, that the patient should be examined with advanced imaging methods in case of suspicion, and the necessary precautions should be taken to prevent peritoneal contamination in case of intraoperative suspicion.

3. Ultrasonography is the recommended first-line imaging method. Routine MRI is not recommended for every preoperative patient and should be performed when malignancy is suspected. A pre-operative endometrial biopsy may only be useful in patients with abnormal uterine bleeding. Its effectiveness in diagnosing sarcomas is very poor.

4. Survival outcomes are worse in uterine sarcomas, even in the early stages, compared to endometrial malignancies.
The morcellation of sarcomas can result in disease progression and worsen survival outcomes compared to non-morcellation.

5 . The peritoneal seeding resulting from morcellation increases the incidence of benign sequelae. These sequelae account for the vast majority of morcellation-related morbidities and should not be ignored.

6. Although it is assumed that morcellation with tissue containment may be protective against negative outcomes, there is not enough evidence regarding the preventive efficacy of this method. Further studies are needed to establish conclusive data.

7. Patients should be informed in detail regarding the advantages of minimally invasive surgery and the risks of morcellation. In patients in whom malignancy is suspected, morcellation should be avoided (or not performed at all), regardless of the patient's consent.

8. In patients who will be operated with a preliminary diagnosis of uterine myoma, intact removal of the uterus may be primarily considered, depending on the patients' fertility preferences and age.

9. Studies should be designed to determine the efficacy of preoperative diagnostic methods and the preventive potential of contained morcellation techniques. These studies should aim for the inclusion of as many centers as possible due to the low prevalence of the disease.

Peer-review: Externally and internally peer-reviewed.

Conflict of Interest: No conflict of interest is declared by the authors.

Financial Disclosure: The authors declared that this study received no financial support.

\section{References}

1. Langenbeck CJM. Nosology and Therapy of Surgical Illnesses, Gottingen, Germany: 1845 .

2. Semm K. Pelviscopy and Hysteroscopy: Color Atlas and Textbook. New York: Schattauer; 1976.

3. Mettler L, Semm K, Lehmann-Willenbrock L, Shah A, Shah P, Sharma R. Comparative evaluation of classical intrafascialsupracervical hysterectomy (CISH) with transuterine mucosal resection as performed by pelviscopy and laparotomy-our first 200 cases. Surg Endosc 1995; 9: 418-23.

4. Perri T, Korach J, Sadetzki S, Oberman B, Fridman E, Ben-Baruch G. Uterine leiomyosarcoma: does the primary surgical procedure matter? Int J Gynecol Cancer 2009; 19: 257-60.

5. Park JY, Park SK, Kim DY, Kim JH, Kim YM, Kim YT, et al. The impact of tumor morcellation during surgery on the prognosis of patients with apparently early uterine leiomyosarcoma. Gynecol Oncol 2011; 122: 255-9.

6. US Food and Drug Administration. Laparoscopic Uterine Power Morcellation in Hysterectomy and Myomectomy: FDA Safety 
Communication, c.2104 Apr 17 (cited 2017 July 6) Available from: https://www.fda.gov/MedicalDevices/Safety/AlertsandNotices

7. FDA UPDATED laparoscopic uterine power morcellation in hysterectomy and myomectomy: FDA safety communication FDA, 24 (2014, November) Retrieved from: http://www.fda. gov/MedicalDevices/Safety/AlertsandNotices/ucm424443.htm [13.09.15]

8. Halaska MJ, Haidopoulos D, Guyon F, Morice P, Zapardiel I, Kesic $\mathrm{V}$, et al. European society of gynecological oncology statement on fibroid and uterine morcellation. Int J Gynecol Cancer 2017; 27: 189-92.

9. Brölmann H, Tanos V, Grimbizis G, Ind T, Philips K, van den Bosch $\mathrm{T}$, et al. Options on fibroid morcellation: a literature review. Gynecol Surg 2015; 12: 3-15.

10. AAGL Advancing Minimally Invasive Gynecology Worldwide. AAGL practice report: morcellation during uterine tissue extraction. J Minim Invasive Gynecol 2014; 21: 517-30.

11. Beckmann MW, Juhasz-Böss I, Denschlag D, Gaß P, Dimpfl T, Harter $\mathrm{P}$, et al. Surgical methods for the treatment of uterine fibroids - risk of uterine sarcoma and problems of morcellation: position paper of the DGGG. Geburtshilfe Frauenheilkd 2015; 75: 148-64.

12. Statement of the Society of Gynecologic Oncology to the Food and Drug Administration's Obstetrics and Gynecology Medical Devices Advisory Committee Concerning Safety of Laparoscopic Power Morcellation. SGO,2014, July. [13.09.15] Available from: https:// www.sgo.org/wp-content/uploads/2014/04/SGO-Testimony-toFDA-on-Power-Morcellation-FINAL.pdf

13. Rousseau M, Morel A, Dechoux S, Bouet PE, Catala L, Lefebvre Lacoeuille $\mathrm{C}$, et al. Can the risks associated with uterine sarcoma morcellation really be prevented? Overview of the role of uterine morcellation in 2018. J Gynecol Obstet Hum Reprod 2018; 47: 341-9.

14. Pritts EA, Vanness DJ, Berek JS, Parker W, Feinberg R, Feinberg $\mathrm{J}$, et al. The prevalence of occult leiomyosarcoma at surgery for presumed uterine fibroids: a meta-analysis. Gynecol Surg 2015; 12 : 165-77.

15. Tan-Kim J, Hartzell KA, Reinsch CS, O'Day CH, Kennedy JS, Menefee SA, et al. Uterine sarcomas and parasitic myomas after laparoscopic hysterectomy with power morcellation. Am J Obstet Gynecol 2015; 212: 594.e1-594.e10.

16. Topdagi Yilmaz EP, Cimilli Senocak GN, Topdagi YE, Aynaoglu Yildiz G, Kumtepe Y. Incidence of occult malignancies identified during hysterectomies performed for benign indications. J Gynecol Obstet Hum Reprod 2020; 49: 101620.

17. Yorgancı A, Meydanlı MM, Kadıoğlu N, Taşkın S, Kayıkçığlu F, Altın $\mathrm{D}$, et al. Incidence and outcome of occult uterine sarcoma: a multicentre study of 18604 operations performed for presumed uterine leiomyoma. J Gynecol Obstet Hum Reprod 2020; 49: 101631.

18. Cohen A, Tulandi T. Long-term sequelae of unconfined morcellation during laparoscopic gynecological surgery. Maturitas 2017; 97: 1-5.

19. Tasci T, Karalok A, Taskin S, Ureyen I, Kimyon G, Tulek F, et al. Does lymphadenectomy improve survival in uterine leiomyosarcoma? Int J Gynecol Cancer 2015; 25: 1031-6.

20. Raine-Bennett T, Tucker LY, Zaritsky E, Littell RD, Palen T, Neugebauer R, et al. Occult uterine sarcoma and leiomyosarcoma: incidence of and survival associated with morcellation. Obstet Gynecol 2016; 127: 29-39.

21. Bogani G, Cliby WA, Aletti GD. Impact of morcellation on survival outcomes of patients with unexpected uterine leiomyosarcoma: a systematic review and meta-analysis. Gynecol Oncol 2015; 137: $167-72$.

22. Oduyebo T, Rauh-Hain AJ, Meserve EE, Seidman MA, Hinchcliff $\mathrm{E}$, George $\mathrm{S}$, et al. The value of re-exploration in patients with inadvertently morcellated uterine sarcoma. Gynecol Oncol 2014; 132: $360-5$
23. Rivard C, Salhadar A, Kenton K. New challenges in detecting, grading, and staging endometrial cancer after uterine morcellation. J Minim Invasive Gynecol 2012; 19: 313-6.

24. Cohen SL, Morris SN, Brown DN, Greenberg JA, Walsh BW, Gargiulo $\mathrm{AR}$, et al. Contained tissue extraction using power morcellation: prospective evaluation of leakage parameters. Am J Obstet Gynecol 2016; 214: 257.e1-257.e6.

25. Solima E, Scagnelli G, Austoni V, Natale A, Bertulessi C, Busacca M, et al. Vaginal uterine morcellation within a specimen containment system: a study of bag integrity. J Minim Invasive Gynecol 2015; 22: 1244-6.

26. Parker WH, Fu YS, Berek JS. Uterine sarcoma in patients operated on for presumed leiomyoma and rapidly growing leiomyoma. Obstet Gynecol 1994; 83: 414-8.

27. Schwartz LB, Diamond MP, Schwartz PE. Leiomyosarcomas: clinical presentation. Am J Obstet Gynecol 1993; 168 (1 Pt 1): 180-3.

28. Bansal N, Herzog TJ, Burke W, Cohen CJ, Wright JD. The utility of preoperative endometrial sampling for the detection of uterine sarcomas. Gynecol Oncol 2008; 110: 43-8.

29. Aviram R, Ochshorn Y, Markovitch O, Fishman A, Cohen I, Altaras $\mathrm{MM}$, et al. Uterine sarcomas versus leiomyomas: gray-scale and Doppler sonographic findings. J Clin Ultrasound 2005; 33: 10-3.

30. Kurjak A, Kupesic S, Shalan H, Jukic S, Kosuta D, Ilijas M. Uterine sarcoma: a report of 10 cases studied by transvaginal color and pulsed Doppler sonography. Gynecol Oncol 1995; 59: 342-6.

31. Bonneau C, Thomassin-Naggara I, Dechoux S, Cortez A, Darai É, Rouzier R. Value of ultrasonography and magnetic resonance imaging for the characterization of uterine mesenchymal tumors. Acta Obstet Gynecol Scand 2014; 93: 261-8.

32. Goto A, Takeuchi S, Sugimura K, Maruo T. Usefulness of Gd-DTPA contrast-enhanced dynamic MRI and serum determination of LDH and its isozymes in the differential diagnosis of leiomyosarcoma from degenerated leiomyoma of the uterus. Int $\mathrm{J}$ Gynecol Cancer 2002; $12: 354-61$.

33. Thomassin-Naggara I, Dechoux S, Bonneau C, Morel A, Rouzier $\mathrm{R}$, Carette MF, et al. How to differentiate benign from malignant myometrial tumours using MR imaging. Eur Radiol 2013; 23: 230614.

34. Lin G, Yang LY, Huang YT, Ng KK, Ng SH, Ueng SH, et al. Comparison of the diagnostic accuracy of contrast-enhanced MRI and diffusion-weighted MRI in the differentiation between uterine leiomyosarcoma / smooth muscle tumor with uncertain malignant potential and benign leiomyoma. J Magn Reson Imaging 2016; 43: $333-42$.

35. Di Cello A, Borelli M, Marra ML, Franzon M, D'Alessandro P, Di Carlo $\mathrm{C}$, et al. A more accurate method to interpret lactate dehydrogenase (LDH) isoenzymes' results in patients with uterine masses. Eur J Obstet Gynecol Reprod Biol 2019; 236: 143-7.

36. Nagai T, Takai Y, Akahori T, Ishida $\mathrm{H}$, Hanaoka T, Uotani T, et al. Novel uterine sarcoma preoperative diagnosis score predicts the need for surgery in patients presenting with a uterine mass. Springerplus 2014; 3: 678.

37. Lynam S, Young L, Morozov V, Rao G, Roque DM. Risk, risk reduction and management of occult malignancy diagnosed after uterine morcellation: a commentary. Womens Health (Lond) 2015; 11: $929-44$.

38. Ricci S, Stone RL, Fader AN. Uterine leiomyosarcoma: epidemiology, contemporary treatment strategies and the impact of uterine morcellation. Gynecol Oncol 2017; 145: 208-16.

39. Graebe K, Garcia-Soto A, Aziz M, Valarezo V, Heller PB, Tchabo N, et al. Incidental power morcellation of malignancy: a retrospective cohort study. Gynecol Oncol 2015; 136: 274-7. 